\title{
BMJ Open Associations between community well- being and hospitalisation rates: results from a cross-sectional study within six US states
}

\author{
Brita Roy (D) , ${ }^{1}$ Carley Riley, ${ }^{2,3}$ Jeph Herrin, ${ }^{4}$ Erica Spatz (D) ${ }^{1,4}$ Brent Hamar, ${ }^{5}$ \\ Kenneth P Kell, ${ }^{6}$ Elizabeth Y Rula, ${ }^{7}$ Harlan Krumholz (D) ${ }^{1,4,8}$
}

To cite: Roy B, Riley C, Herrin J, et al. Associations between community well-being and hospitalisation rates: results from a cross-sectional study within six US states. BMJ Open 2019;9:e030017. doi:10.1136/ bmjopen-2019-030017

\section{- Prepublication history and} additional material for this paper are available online. To view these files, please visit the journal online (http://dx.doi org/10.1136/bmjopen-2019030017).

Received 23 February 2019 Revised 24 October 2019 Accepted 07 November 2019
Check for updates

\section{(C) Author(s) (or their} employer(s)) 2019. Re-use permitted under CC BY-NC. No commercial re-use. See rights and permissions. Published by BMJ.

For numbered affiliations see end of article.

Correspondence to

Dr Brita Roy; brita.roy@yale.edu

\section{ABSTRACT}

Objective To evaluate the association between

community well-being, a positively framed,

multidimensional assessment of the health and quality of life of a geographic community, and hospitalisation rates. Design Cross-sectional study

Setting Zip codes within six US states (Florida, lowa, Nebraska, New York, Pennsylvania and Utah)

Main outcome measures Our primary outcome was age-adjusted, all-cause hospitalisation rates in 2010; secondary outcomes included potentially preventable disease-specific hospitalisation rates, including cardiovascular-related, respiratory-related and cancerrelated admissions. Our main independent variable was the Gallup-Sharecare Well-Being Index (WBI) and its domains (life evaluation, emotional health, work environment, physical health, healthy behaviours and basic access)

Results Zip codes with the highest quintile of wellbeing had 223 fewer hospitalisations per 100000 (100k) residents than zip codes with the lowest well-being. In our final model, adjusted for WBI respondent age, sex, race/ ethnicity and income, and zip code number of hospital beds, primary care physician density, hospital density and admission rates for two low-variation conditions, a 1 SD increase in WBI was associated with 5 fewer admissions/100k (95\% Cl 4.0 to 5.8; $p<0.001)$. Results were similar for cardiovascular-related and respiratoryrelated admissions, but no association remained for cancer-related hospitalisation after adjustment. Patterns were similar for each of the WBI domains and all-cause hospitalisations.

Conclusion and relevance Community well-being is inversely associated with local hospitalisation rates. In addition to health and quality-of-life benefits, higher community well-being may also result in fewer unnecessary hospitalisations.

\section{INTRODUCTION}

Hospitalisation rates vary widely across the USA, with county-level hospitalisation rates for ambulatory sensitive conditions ranging from 14 to 281 hospitalisations per 1000 Medicare enrollees in 2011. ${ }^{1}$ This 20 -fold variation in potentially preventable hospitalisation
Strengths and limitations of this study

- In this cross-sectional study, we linked data from all-payer claims databases from six diverse US states with the most comprehensive measure of well-being in the USA, the Gallup-Sharecare WellBeing Index, by zip code.

- Using these data, this study assessed whether the well-being of a zip code was associated with the age-adjusted hospitalisation rates of the population living within that zip code.

- We summarised rates of hospitalisation by quintile of zip code well-being, and examined associations between zip code well-being and age-adjusted hospitalisation rates before and after adjustment for sociodemographic characteristics, hospital intensity variables and low-variation conditions.

- This is a cross-sectional study, and it cannot assess causation, but assessing whether a relationship exists between community well-being and hospitalisation rates is an important initial step.

- Without data on the well-being of those hospitalised, we are unable to assess whether community wellbeing is associated with hospitalisation rates independent of individual-level well-being.

rates by location suggests that characteristics of the community in which patients live may contribute to higher or lower hospitalisation rates.

As part of efforts to reduce unnecessary hospitalisation rates, health systems and other stakeholders have begun to seek modifiable community properties that are associated with lower hospitalisation rates, and may, therefore, serve as potential targets for intervention. Prior studies have identified some community factors that are linked to rates of hospitalisations, ${ }^{2}$ including housing instability and access to primary care, ${ }^{23}$ as well as road and airport traffic noise, air quality and smoking policies. $^{4-8}$ 
Emerging evidence suggests that psychosocial factors may also be linked to hospitalisation rates. At the individual level, a broad measure of subjective well-being-a comprehensive measure comprised of physical and emotional health, healthy behaviours, life evaluation, work environment and access to basic needs-was associated with fewer emergency department visits, hospitalisations and healthcare costs. ${ }^{910}$ It is plausible that this inverse association with well-being extends to the community level. Our team has previously linked higher population well-being with lower Medicare spending, after adjustment for income, urbanicity and healthcare system capacity. ${ }^{11}$ In addition, related community-level positive psychosocial factors, such as social capital, have been reported to be protective of cardiovascular hospitalisations in prospective studies. However, the relationship between population well-being and hospitalisation risk has yet to be examined. Therefore, we sought to evaluate a community-level association between well-being and hospitalisation, hypothesising that higher community well-being is associated with lower rates of hospitalisation.

\section{METHODS}

\section{Overview}

We linked data from a comprehensive, multidimensional assessment of well-being, the Gallup-Sharecare Well-Being Index (WBI), with data on hospitalisation rates from a diverse set of six states from state all-payer claims databases or the Agency for Healthcare Research and Quality's Healthcare Costs and Utilization Project (HCUP). All data were from the year 2010, as this was the most recent year for which we had access to HCUP data and the year that had the largest sample size for our covariates. All data were aggregated and linked at the zip code level. We performed a cross-sectional study to assess the correlation between community well-being and hospitalisation rates.

\section{Sample}

We included data on all adult and paediatric hospitalisations from zip codes within six states: Florida, Iowa, Nebraska, New York, Pennsylvania and Utah. We selected states with available data on hospitalisation rates by zip code for the calendar year 2010 through state all-payer claims databases or the HCUP. Within these restrictions, we aimed to choose a diverse sample of states from different regions of the USA and with urban, suburban and rural areas. We excluded hospitalisations for patients with listed home zip codes outside the state where they were hospitalised. We also excluded zip codes with fewer than 10 survey participants in the WBI in the year 2010.

\section{Community well-being}

Our main independent variable was the composite wellbeing score, as measured by the Gallup-Sharecare WBI. We used WBI data from 01 January 2010 to 31 December 2010, aggregated by zip code, to assess community well-being.
The Gallup-Sharecare WBI is an ongoing telephonebased survey administered to a random sample of $500-1000$ adults in the USA daily, 350 days per year, since 2008. The random sample includes adults aged 18 years and older residing in the USA, who speak either English or Spanish and have either a landline or cellular phone. Gallup used a structured sampling design to obtain representative data from all 50 states and the District of Columbia. $^{12}$

The WBI was developed based on the work of psychology experts. ${ }^{1314}$ Briefly, survey items that aligned with previous research on well-being were initially compiled by experts in the field. ${ }^{15}{ }^{16}$ Based on reviews of the literature, items were selected to encompass both hedonic well-being (ie, people's feelings and thoughts about their lives) ${ }^{17}$ and eudemonic well-being (ie, an individual's judgments about the meaning and purpose in one's life), ${ }^{18}$ and thus incorporated items assessing daily emotional experience and a wide variety of evaluative domains, such as overall life, standard of living, and satisfaction with community, work, relationships and personal health. Factor analysis using data from a large, representative national sample was then used to determine the final set of questions. Criterion validity of regionally aggregated data was established by examining correlations with regional health and socioeconomic indicators. ${ }^{19}$ Subsequently, principal component analyses and confirmatory factor analyses were used to create an instrument valid for measuring well-being at the individual level. The individual wellbeing measure has acceptable reliability, and internal and external validity. ${ }^{20}$

The WBI includes 40 self-reported items organised into six domains representing key aspects of wellbeing $^{15}$ : life evaluation (life satisfaction and optimism), emotional health (positive and negative affect and the presence or absence of depression), work environment (job satisfaction and trust and respect in the workplace among respondents who report being employed), physical health (chronic disease and recent illness), healthy behaviours (smoking, exercise, and fruit and vegetable consumption) and basic access (perceived safety, housing and healthcare access). ${ }^{12}$ Each domain is measured on a scale of $0-100$, and the composite well-being score is an unweighted mean of all the six domains. ${ }^{21}$

\section{Hospitalisaton rates}

Our dependent variable was age-adjusted, all-cause hospitalisation rate. Hospitalisation rates by patient's residence zip code were obtained using all-payer claims databases or data from the HCUP from Florida, Iowa, Nebraska, New York, Pennsylvania and Utah. Patients with out-of-state residence zip codes were excluded. Rates were expressed in number per 100000 (100k).

To guide future work on reducing potentially preventable hospitalisations, we also examined rates of cardiovascular-related, respiratory-related and specific cancer-related hospitalisations as additional dependent variables. Major cardiovascular disease (CVD) discharges 
(eg, ischaemic heart disease, hypertensive disease, rheumatic heart disease and stroke) were identified by International Classification of Disease, Ninth Revision, Clinical Modification (ICD-9-CM) codes of 390-448 as the primary diagnosis. Respiratory-related hospitalisations included hospital discharges for asthma, chronic obstructive pulmonary disease and pneumonia (ICD-9-CM primary diagnosis codes 480-496). Specific cancers included in this study were those with standard recommended screening protocols, including breast cancer, lung cancer, colon cancer and cervical cancer (ICD-9-CM primary discharge diagnosis codes 153-4, 162, 174 and 180).

\section{Covariates}

Covariates included zip code population estimates for age, sex, race/ethnicity and median income, obtained from the 2010 US Census. We also included the following healthcare intensity variables obtained from the Area Health Resource File ${ }^{22}$ : number of hospital beds, primary care physician density and hospital density. Hospital beds were defined as the number of beds regularly maintained (set up and staffed for use) for inpatients as of the close of the reporting period. Primary care physician density was defined as non-Federal doctors of medicine and doctors of osteopathy providing direct patient care who practice principally in one of the four primary care specialtiesgeneral or family practice, general internal medicine, paediatrics, and obstetrics and gynaecology per 100k population. Hospital density was defined as the number of acute care hospitals per $100 \mathrm{k}$ population. Finally, to account for differences in hospital referral regions and volume, we included admission rates for two low-variation conditions for hospitalisation not included as a secondary outcome (hip fracture and gastrointestinal bleeding) from the state all-payer claims databases or data from the HCUP. ${ }^{23}$

\section{Analysis}

We first described the distribution of well-being scores and prevalence of healthcare intensity variables across included zip codes, stratified by quintile of hospitalisation rates. Next, we described the mean all-cause, cardiovascular, respiratory and cancer-related hospitalisation rates by quintile of composite well-being score and by each well-being domain.

We then estimated three nested multivariable linear regression models to explore associations between 1 SD increase in the composite well-being score and each well-being domain with zip code hospitalisation rates. We first estimated an unadjusted model (model 1) which included only indicators for state, and sequentially adjusted for additional sets of covariates. A second model (model 2) adjusts for population age, sex, race and income, and admission rates for low-variation conditions. The final model (model 3) further adjusts model 2 for healthcare intensity variables. We repeated these analyses for cardiovascular-related, respiratory-related, and cancer-related hospitalisations. We used the method of Belsley, Kuh and Welsch to assess the covariates for collinearity; using their criteria, we excluded the proportion of respondents aged between 65 and 84 years from the models. ${ }^{24}$

All analyses were performed using Stata V.15.0.

\section{Patient and public involvement}

No patients or the public was involved in the planning and design of this study.

\section{RESULTS}

We included 1487 zip codes in our analysis. The mean WBI score ranged from 56 in the lowest quintile up to 78.2 in the highest quintile (table 1). Zip codes with higher WBI tended to have fewer adults aged over 65 years, though there was no difference in any other age groups. Zip codes with higher WBI also had higher median household income, but there was no difference in per cent white residents. In addition, zip codes with higher WBI had more general practitioners per 100k residents. No other consistent patterns of healthcare intensity variables were noted across quintiles of well-being.

As the zip code WBI increased from the lowest to highest quintile, the mean number of hospitalisations per $100 \mathrm{k}$ residents decreased (figure 1). Zip codes in the highest quintile of well-being had $17 \%$ fewer

Table 1 Differences in mean sociodemographic factors and healthcare intensity variables across quintiles of well-being ( $n=1487$ zip codes)

\begin{tabular}{llllllc}
\hline & Q1 & Q2 & Q3 & Q4 & Q5 & P trend \\
\hline Well-being & 56.0 & 64.0 & 67.9 & 71.5 & 78.2 & N/A \\
\% age>65 years & 11.1 & 11.2 & 10.5 & 10.7 & 10.5 & 0.02 \\
\% white & 86.9 & 89.2 & 89.3 & 90.1 & 91.5 & 0.62 \\
Median household income (thousands) & 48.0 & 51.1 & 57.6 & 60.4 & 64.5 & $<0.001$ \\
PCP/100k & 27.1 & 28.6 & 31.5 & 31.4 & 31.0 & $<0.001$ \\
Hospitals/100k & 2.9 & 2.2 & 2.4 & 2.8 & 3.1 & 0.23 \\
Hospital beds/100k & 0.3 & 0.3 & 0.4 & 0.3 & 0.3 & 0.38 \\
\hline
\end{tabular}

100k, 100 000; N/A, not available; PCP, primary care provider; Q, quintile. 


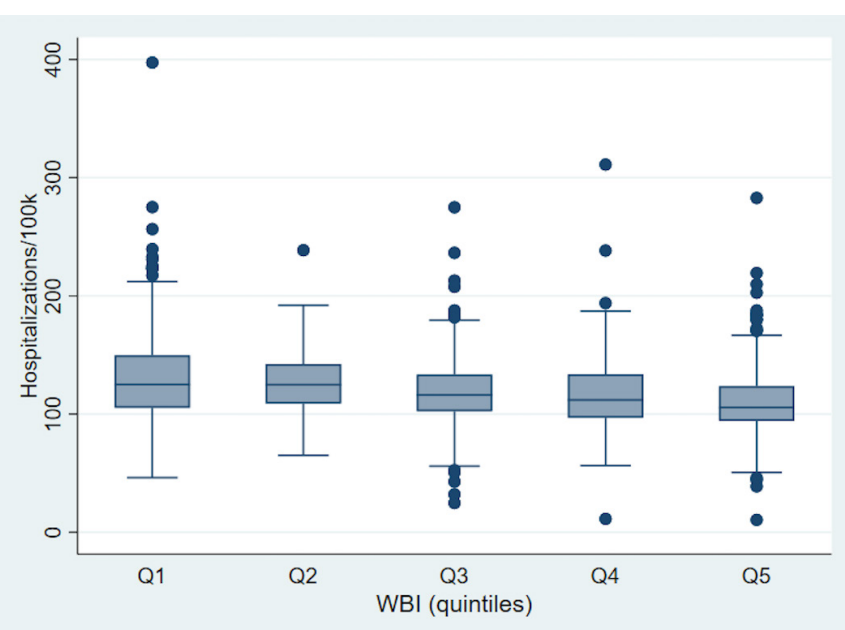

Figure 1 Median number and IQR of age-standardised and sex-standardised hospitalisations/100 000 (100k) population across quintiles of well-being ( $n=1487$ zip codes). WBI, wellbeing index.

hospitalisations than zip codes in the lowest quintile of well-being (an absolute difference of 223 per 100k residents). After adjustment for age, sex, race, income and healthcare intensity variables, zip codes in the highest quintile of well-being had $9 \%$ fewer hospitalisations than zip codes in the lowest quintile of well-being (absolute difference of 12 per $100 \mathrm{k}$ residents; online supplementary appendix). The number of hospitalisations per 100k decreased in a stepwise fashion across quintiles of wellbeing. Similar patterns of smaller magnitude were seen for cardiovascular-related (absolute difference: 35/100k; $20 \%$ fewer hospitalisations), respiratory-related (absolute difference: 19/100k; 26\% fewer hospitalisations) and cancer-related hospitalisations (absolute difference: 2/100k; $17 \%$ fewer hospitalisations).

In our unadjusted model, a 1 SD higher WBI was associated with 7.3 fewer all-cause hospital admissions/100k $(\mathrm{p}<0.001)$ (table 2). After adjustment for demographics and low-variation causes for hospital admission, a 1 SD higher WBI was associated with 5.5 fewer hospital admissions/100k. In our fully adjusted model, a 1 SD higher WBI was associated with 5 fewer all-cause hospital

Table 2 Unadjusted and adjusted associations between $1 \mathrm{SD}$ increase in well-being and all-cause, cardiovascularrelated, respiratory-related and cancer-related hospitalisations per 100000 residents

\begin{tabular}{llll}
\hline & Model 1 & Model 2 & Model 3 \\
\hline All-cause & $-7.3^{\star *}$ & $-5.5^{\star *}$ & $-4.9^{\star *}$ \\
Cardiovascular & $-0.99^{\star *}$ & $-0.67^{\star *}$ & $-0.56^{\star *}$ \\
Respiratory & $-0.69^{\star *}$ & $-0.42^{\star *}$ & $-0.33^{\star *}$ \\
Cancer & $-0.05^{\star}$ & $-0.04^{\star}$ & -0.04 \\
\hline
\end{tabular}

Model 1: unadjusted; model 2: adjusted for sociodemographics and low-variation admissions; and model 3: further adjusted for healthcare intensity variables.

${ }^{*} p<0.05$ and ${ }^{* *} p<0.001$. admissions/100k $(\mathrm{p}<0.001)$. Results were similar for cardiovascular-related and respiratory-related admissions, but no association remained for cancer-related hospitalisation after adjustment. The $\mathrm{R}^{2}$ values for the fully adjusted WBI model ranged from 0.13 for cancer admissions to 0.43 for CVD admissions; the model for all-cause admissions had an $\mathrm{R}^{2}=0.38$ (table 3 ).

In general, similar patterns were seen for each of the well-being domains. All domains of well-being were inversely associated with all-cause hospitalisations in unadjusted and adjusted models. The strongest inverse relationships with all-cause hospital admissions were noted with a $1 \mathrm{SD}$ increase in the basic access (14.7 fewer admissions/100k; $\mathrm{p}<0.001$ ), physical health (6.6 fewer admissions/100k; $\mathrm{p}<0.001)$ and emotional health (6.6 fewer admissions / 100k; $\mathrm{p}<0.001$ ) domains in unadjusted models. In fully adjusted models, all-cause hospitalisations were most strongly associated with the basic access (8.3 fewer admissions/100k; $\mathrm{p}<0.001$ ), physical health (4.9 fewer admissions/100k; $\mathrm{p}<0.001$ ) and emotional health (4.6 fewer admissions/100k; $\mathrm{p}<0.001$ ) domains.

\section{DISCUSSION}

Our study examines the association between a holistic, multidimensional assessment of well-being and hospitalisation rates by zip code. We found that higher community well-being was associated with lower all-cause, cardiovascular and respiratory hospitalisation rates, after controlling for sociodemographic and healthcare intensity variables, including density of primary care physicians. If all zip codes in the USA had well-being scores in the highest quintile, based on our findings, we would expect approximately 100k fewer hospitalisations yearly, saving nearly US $\$ 1$ billion in healthcare costs. These results suggest that beyond access to care and social risk factors, there are additional community attributes that may influence local hospitalisation rates.

Community well-being is modifiable and supporting programmes and policies to foster community well-being should be a society's end goal. ${ }^{25-27}$ Our results suggest that promoting community well-being may have an additional benefit of curbing unnecessary hospitalisation rates, as well as supporting other beneficial population health outcomes, including longer life expectancy and lower rates of preterm birth. ${ }^{28-30}$ Our team also recently reported that Medicare spent a mean of US\$992 less per beneficiary who lived in counties with the highest quintile of well-being compared with those who lived in counties with the lowest quintile of well-being. ${ }^{11}$ Because hospitalisations are one of the largest drivers of healthcare costs, results from the present study support and expand our prior finding, in that the well-being of a community is linked to healthcare utilisation and costs across all ages and payers. In both studies, basic access and emotional health were among the three domains most strongly associated with the outcome. As hospitals and health systems seek to achieve lower total costs of care in value-based 
Table 3 Fully adjusted models assessing associations between zip code WBI and all-cause, cardiovascular-related (CVD), respiratory-related and cancer-related hospital admissions

\begin{tabular}{|c|c|c|c|c|}
\hline & All-cause & CVD & Respiratory & Cancer \\
\hline & Coeff (SE) & Coeff (SE) & Coeff (SE) & Coeff (SE) \\
\hline WBI & $-48.55(8.87)$ & $-5.58(1.40)$ & $-3.26(0.93)$ & $-0.34(0.19)$ \\
\hline \multicolumn{5}{|l|}{ State } \\
\hline FL & ref & ref & ref & ref \\
\hline $\mathrm{IA}$ & $-20.41(4.26)$ & $-4.23(0.67)$ & $-2.22(0.45)$ & $-0.11(0.09)$ \\
\hline NE & $-18.26(4.44)$ & $-4.67(0.70)$ & $-1.70(0.47)$ & $0.03(0.10)$ \\
\hline NY & $-20.82(3.67)$ & $-3.80(0.58)$ & $-2.01(0.39)$ & $0.07(0.08)$ \\
\hline PA & $-2.62(3.26)$ & $-0.64(0.51)$ & $-1.25(0.34)$ & $0.05(0.07)$ \\
\hline UT & $-24.22(3.93)$ & $-7.73(0.62)$ & $-3.21(0.41)$ & $-0.36(0.09)$ \\
\hline$\%$ female & $0.09(0.04)$ & $0.01(0.01)$ & $0.00(0.00)$ & $0.00(0.00)$ \\
\hline \multicolumn{5}{|l|}{ Age, years } \\
\hline$\%$ age $25-44$ & $0.14(0.06)$ & $0.03(0.01)$ & $0.01(0.01)$ & $0.00(0.00)$ \\
\hline$\%$ age $45-64$ & $-0.03(0.04)$ & $-0.00(0.01)$ & $0.00(0.01)$ & $0.00(0.00)$ \\
\hline$\%$ age $65-85$ & $-0.21(0.11)$ & $-0.03(0.02)$ & $-0.03(0.01)$ & $0.00(0.00)$ \\
\hline \multicolumn{5}{|l|}{ Income } \\
\hline$\% 12-35 k$ & $-0.02(0.05)$ & $0.01(0.01)$ & $0.00(0.01)$ & $-0.00(0.00)$ \\
\hline$\% 36-59 k$ & $-0.04(0.06)$ & $0.00(0.01)$ & $-0.00(0.01)$ & $-0.00(0.00)$ \\
\hline$\%$ 60-120k & $-0.25(0.06)$ & $-0.03(0.01)$ & $-0.03(0.01)$ & $-0.01(0.00)$ \\
\hline$\%>120 k$ & $-0.37(0.08)$ & $-0.06(0.01)$ & $-0.05(0.01)$ & $-0.01(0.00)$ \\
\hline \multicolumn{5}{|l|}{ Race } \\
\hline$\% A A$ & $0.84(0.07)$ & $0.10(0.01)$ & $0.06(0.01)$ & $0.01(0.00)$ \\
\hline$\%$ Hispanic & $0.75(0.27)$ & $0.05(0.04)$ & $0.04(0.03)$ & $-0.00(0.01)$ \\
\hline$\%$ Asian & $-0.29(0.28)$ & $-0.11(0.04)$ & $-0.06(0.03)$ & $-0.01(0.01)$ \\
\hline$\%$ other & $0.41(0.12)$ & $0.04(0.02)$ & $0.03(0.01)$ & $-0.00(0.00)$ \\
\hline GPs/100k & $-2.81(0.61)$ & $-0.60(0.10)$ & $-0.44(0.06)$ & $-0.02(0.01)$ \\
\hline Hosp/100k & $-2.79(0.94)$ & $-0.40(0.15)$ & $0.35(0.10)$ & $-0.05(0.02)$ \\
\hline Hospital beds/100k & $7.44(0.77)$ & $0.76(0.12)$ & $0.43(0.08)$ & $0.08(0.02)$ \\
\hline Intercept & $151.46(8.52)$ & $21.21(1.34)$ & $9.34(0.90)$ & $1.26(0.19)$ \\
\hline $\mathbf{R}^{2}$ & 0.39 & 0.43 & 0.29 & 0.13 \\
\hline
\end{tabular}

AA, African-American; Coeff, coefficient; CVD, cardiovascular disease; FL, Florida; GPs, general practitioners; Hosp, hospital(s); IA, lowa; k, thousands; NE, Nebraska; NY, New York; PA, Pennsylvania; ref, reference; UT, Utah; WBI, well-being index.

payment arrangements, paying attention to these community psychosocial attributes may foster success.

We report cross-sectional associations at the zip code level, and thus, we are unable to make causal inferences. However, it suggests that the efforts communities and policymakers are engaged in globally to improve community well-being may also have a modest effect on reducing hospitalisation rates. Our team recently reported that there are modifiable community characteristics, such as education levels, adequate income, diversity, rates of preventive care and rates of active commuting, that are associated with higher well-being of community residents. ${ }^{31}$ In addition, a prospective study in which municipal officials approved and permitted community member-driven environmental changes (eg, street murals, public benches and planter boxes, in public spaces) also resulted in improved well-being. ${ }^{32}{ }^{33}$ Residents within a two-block radius of the transformed sites were systematically sampled and reported improvements in mental health, increased sense of community and an overall expansion of social capital. More comprehensive, longitudinal studies, such as the ongoing Well London Study, ${ }^{25} 26$ are needed to assess whether systemic community-based interventions influence well-being, and if they result in better population health outcomes, as hypothesised.

In general, these community-based interventions that improve well-being, such as improving housing conditions, income, safety and education, are linked to lower rates of hospitalisation. As such, promoting community well-being as a target outcome is likely to also result in 
reducing unnecessary hospitalisations as community conditions are improved. However, our study suggests that there is a small but important additional reduction in hospitalisations attributable to higher community well-being itself. There are several potential mechanisms underlying this observed association. First, it is possible that the observed association is simply a result of aggregating individuals with higher well-being and their associated lower rate of hospitalisation. ${ }^{28}$ In two unique large employer-based populations, higher individual well-being predicted fewer hospitalisations and emergency department visits over the next 12 months. ${ }^{9}{ }^{10}$ Similarly, among a large, multistate sample of Veterans, 10-point decrements in the physical and mental component scores of the Short Form-36 health-related quality of life were associated with higher rates of hospitalisations, after adjusting for sociodemographics, smoking and prior healthcare utilisation. ${ }^{34}$ Due to limitations in the data we had available, we were unable to test the relationship between individual and community well-being in this study, but even if the observed zip code-level association is due to the effects of higher aggregate individual resident well-being, it suggests that certain communities embody characteristics that foster higher resident well-being - a positive end in and of itself.

Community well-being may influence hospitalisation rates above and beyond the effect of individual well-being. This hypothesised extension of individual well-being to community well-being is plausible in that components of well-being, including happiness and altruism, that have been reported to diffuse across one's social network in experimental and prospective observational studies. ${ }^{35} 36$ An increase in happiness of one person in a geographic community led to an increase in happiness among friends and family members who lived within one mile, but did not influence the happiness of co-workers, supporting the theory that higher well-being of individual residents in a community increases the well-being of the entire community. ${ }^{35}$ This logic is further supported by prior studies reporting other community-level positive psychosocial attributes are also directly associated with better health outcomes and inversely associated with healthcare utilisation. ${ }^{37}{ }^{38}$ Our domain-specific analysis is aligned with these prior studies, as the emotional WBI alone was independently associated with fewer hospitalisations. Further, a systematic review of prospective, multilevel studies generally found direct relationships between positive community psychosocial attributes, such as social cohesion, social capital and collective efficacy, and health outcomes. Social capital was specifically protective of cardiovascular-related hospitalisations. ${ }^{39}$ After accounting for individual-level risk factors, residents living in neighbourhoods with low social capital had approximately $20 \%$ or $30 \%$ higher risk of first hospitalisation for fatal or nonfatal coronary disease, among men and women, respectively, over a 2 -year period. ${ }^{40}$

There are several potential mechanisms by which positive community psychosocial factors like well-being could exert an effect on hospitalisations: supporting healthy behaviours and social support, lowering the physiologic stress response and increasing percieved access to care. ${ }^{41}$ Community social cohesion and connectedness have been reported to be linked to the adoption of physical activity and not smoking, which influence the incidence of cardiovascular-related and respiratory-related hospitalisations. ${ }^{42-45}$ These associations persisted after adjustment for individual-level sociodemographics. These social factors are thought to influence health behaviours by promoting the spread of health information or increasing the likelihood that healthy norms of behaviour are adopted. ${ }^{43} 4647$ In addition to supporting better health behaviours, stronger social support has been directly linked to fewer hospitalisations. Among older adults with heart failure, those with high levels of social support experienced fewer hospitalisations compared with those with moderate or low social support, in a graded fashion, over a 6.5-month follow-up period. ${ }^{48}$ Further, among multifactorial models predicting risk for hospital readmission, inclusion of social support variables improved overall model performance compared with using sociodemographic and clinical factors alone, supporting its unique and additive role in possibly preventing unnecessary hospitalisations. ${ }^{49}$

Higher community well-being may also reduce hospitalisation rates by reducing or buffering the stress response. ${ }^{50-52}$ Chronic stress results in increased inflammation and higher allostatic load, which may reduce healing from low-acuity conditions and increase risk of CVD, thus resulting in higher rates of all-cause and cardiovascular-related hospital admissions, consistent with our findings. ${ }^{53-57}$ Most of the work supporting this physiologic pathway has been performed at the individual level, with higher levels of optimism and life satisfaction being associated with lower levels of chronic inflammation and incident CVD and mortality. ${ }^{58-63}$ But, because these positive psychologic factors propagate across social groups, these findings may extend to the community level as well, and emerging evidence suggests that higher levels of neighbourhood social well-being are indeed associated with lower levels of perceived chronic stress among residents. ${ }^{52}$ This logic is further supported by findings from a large population-based cohort study that reported that groups with the highest quintile of perceived stress experienced an approximately 1.5-fold higher risk of hospitalisation for ambulatory sensitive conditions, after adjusting for demographics, predisposing conditions, multimorbidity and socioeconomic factors. ${ }^{64}$

Finally, perceived access to healthcare, beyond objective access to healthcare, is another mechanism by which communities with higher well-being may benefit. Higher well-being is associated with greater perceived access to healthcare ${ }^{65}$ and prior studies report inverse associations between self-reported access to care and preventable hospitalisations in other US states and in countries with universal access to healthcare. ${ }^{66}{ }^{67}$ In an Australian study, perceived access to healthcare was associated with 
lower rates of admission for ambulatory sensitive conditions after controlling for propensity to seek healthcare, prevalence of ambulatory sensitive conditions, disease burden and the supply of primary care physicians. ${ }^{67}$ Our results strengthen these findings. Though we controlled for objective measures of access to healthcare, including density of primary care physicians, number of hospital beds, hospital density and admission rates for two lowvariation conditions, the basic access index-which includes perceived access to healthcare and other basic needs-remained associated with lower rates of hospitalisation.

While the basic access index and the physical health domains of well-being are expected to be associated with fewer hospitalisations, other domains of the WBI, including better emotional health and overall life evaluation, were also associated with lower hospitalisation rates. The strength of the inverse association between emotional health and hospitalisation rates was similar to that of physical health and the composite WBI. These findings support the hypothesis that domains of wellbeing beyond physical health and access to basic needs should not be overlooked in their role supporting population health.

Our study has several limitations that should be considered when interpreting results. First, this was a cross-sectional study, so no implications about the directionality of the observed association or causation may be inferred. Though we reviewed the evidence supporting the hypothesis that higher community well-being leads to lower hospitalisation rates, it is also possible that frequent hospitalisations result in depressed well-being. However, hospital admissions affect only a portion of the community population, so it is less likely to be able to influence community well-being. It is also possible that an unknown confounding variable explains the observed inverse relationship between higher well-being and lower hospitalisation rates. However, we controlled for multiple healthcare access factors, as well as demographic variables, making it less likely. In addition, because we were limited to zip codes that had at least 10 participants in the WBI survey, we were only able to include more populated zip codes. As such, our findings may be less representative of rural or less densely populated communities. Further, we were unable to account for disease prevalence in our study, which may impact hospitalisation rates. However, we did control for hospitalisation for low-variation conditions, and the states included do not have known marked differences in the prevalence of cardiovascular or respiratory diseases. Finally, though we tried to include a diverse sample of states, we were limited to those that had statewide all-payer claims data available and that we had access to. We did not include states from the Southeast nor the West Coast, so findings may be less generalisable to those regions.

\section{CONCLUSION}

Higher community well-being was associated with lower rates of all-cause, cardiovascular and respiratory hospital admissions, even after adjusting for sociodemographic and healthcare intensity factors. Though it remains to be tested, these results suggest that policies that promote community well-being may also reduce hospitalisation rates.

\section{Author affiliations}

${ }^{1}$ Internal Medicine, Yale School of Medicine, New Haven, Connecticut, USA ${ }^{2}$ Pediatrics, Cincinnati Children's Hospital Medical Center, Cincinnati, Ohio, USA ${ }^{3}$ Pediatrics, University of Cincinnati College of Medicine, Cincinnati, Ohio, USA ${ }^{4}$ Center for Outcomes Research and Evaluation, Yale-New Haven Health, New Haven, Connecticut, USA

${ }^{5}$ Sharecare Inc, Atlanta, Georgia, USA

${ }^{6}$ Tivity Health, Nashville, Tennessee, USA

${ }^{7}$ Tivity Health, Franklin, Tennessee, USA

${ }^{8}$ Health Policy and Management, Yale School of Public Health, New Haven, Connecticut, USA

Twitter Brita Roy @Broy3445, Carley Riley @Carley_Riley and Erica Spatz @ SpatzErica

Acknowledgements We would like to acknowledge the generous support of Ashlin Jones and Larissa Loufman in the design of this study and preparation of the manuscript.

Contributors $B R$ and $C R$ participated in the initial conception of the study. BR, CR, $\mathrm{JH}, \mathrm{ES}, \mathrm{KPK}, \mathrm{EYR}$ and HK contributed to the study design. KPK, EYR and BH provided access to these data. JH performed all analyses. BR, CR, JH, ES, KPK, EYR and HK interpreted data. BR drafted the initial manuscript. CR, JH, ES, BH, KPK, EYR and HK provided substantive revisions to the manuscript and its final approval. All the authors are guarantors.

Funding This study was supported in part by the Robert Wood Johnson Foundation Clinical Scholars Programme and the Agency for Healthcare Research and Quality (K12 HS023000).

Disclaimer Funders had no role in the design or execution of this study.

Competing interests Partial support from the Agency for Healthcare Research and Quality (BR and ES), the Robert Wood Johnson Foundation (CR and BR) and the Veterans Administration (BR) for the submitted work. CR and BR receive funding from the Institute for Healthcare Improvement to support their effort in developing and implementing the measurement framework for the 100 Million Healthier Lives initiative. BH, EYR and KPK are current or former employees and shareholders of the Healthways corporation (acquired by Sharecare), the company that developed the measure of well-being used in this article. ES, JH and HK also report receiving support from the Centers for Medicare and Medicaid Services. HK is a recipient of research agreements from Medtronic and Johnson \& Johnson (Janssen), through Yale, to develop methods of clinical trial data sharing; is the recipient of a grant from Medtronic and the Food and Drug Administration, through Yale, to develop methods for postmarket surveillance of medical devices; works under contract with the Centers for Medicare and Medicaid Services to develop and maintain performance measures; chairs a cardiac scientific advisory board for UnitedHealth; is a participant/participant representative of the IBM Watson Health Life Sciences Board; is a member of the advisory board for Element Science and the physician advisory board for Aetna; and is the founder of Hugo, a personal health information platform.

\section{Patient consent for publication Not required.}

Ethics approval This study was approved by the Yale University Institutional Review Board.

Provenance and peer review Not commissioned; externally peer reviewed.

Data availability statement Data are available in a public, open access repository.A de-identified data set with zip-code resident well-being data from Gallup-Sharecare linked to all-cause hospitalization rates is available on ICSPR Open at: https://www.openicpsr.org/openicpsr/project/115103/version/v1/view.

Open access This is an open access article distributed in accordance with the Creative Commons Attribution Non Commercial (CC BY-NC 4.0) license, which permits others to distribute, remix, adapt, build upon this work non-commercially, and license their derivative works on different terms, provided the original work is properly cited, appropriate credit is given, any changes made indicated, and the use is non-commercial. See: http://creativecommons.org/licenses/by-nc/4.0/. 
ORCID iDs

Brita Roy http://orcid.org/0000-0002-3782-0104

Erica Spatz http://orcid.org/0000-0002-1557-7713

Harlan Krumholz http://orcid.org/0000-0003-2046-127X

\section{REFERENCES}

1 Catlin B, Jovaag A, Givens M, et al. 2016 County health rankings: key findings report. University of Wisconsin Population Health Institute, 2016.

2 Herrin J, St Andre J, Kenward K, et al. Community factors and hospital readmission rates. Health services research 2014.

3 Reid KW, Kushel MB. Association between the level of housing instability, economic standing and health care access: a metaregression. J Health Care Poor Underserved 2008;19:1212-28.

4 de Kluizenaar $\mathrm{Y}$, van Lenthe $\mathrm{F}$, Visschedijk $\mathrm{AH}$, et al. Road traffic noise, air pollution components and cardiovascular events. Noise Health 2013;15:388-97.

5 Correia AW, Peters JL, Levy JI, et al. Residential exposure to aircraft noise and hospital admissions for cardiovascular diseases: multiairport retrospective study. BMJ 2013;347:f5561.

6 Sims M, Maxwell R, Gilmore A. Short-Term impact of the smokefree legislation in England on emergency hospital admissions for asthma among adults: a population-based study. Thorax 2013;68:619-24.

7 Bell ML, Zanobetti A, Dominici F. Evidence on vulnerability and susceptibility to health risks associated with short-term exposure to particulate matter: a systematic review and meta-analysis. Am J Epidemiol 2013;178:865-76.

8 Shah ASV, Langrish JP, Nair H, et al. Global association of air pollution and heart failure: a systematic review and meta-analysis. Lancet 2013;382:1039-48.

9 Gandy WM, Coberley C, Pope JE, et al. Well-Being and employee Health-How employees' well-being scores interact with demographic factors to influence risk of hospitalization or an emergency room visit. Popul Health Manag 2014;17:13-20.

10 Harrison PL, Pope JE, Coberley CR, et al. Evaluation of the relationship between individual well-being and future health care utilization and cost. Popul Health Manag 2012;15:325-30.

11 Riley C, Roy B, Herrin J, et al. Association of the overall well-being of a population with health care spending for people 65 years of age or older. JAMA Network Open 2018;1:e182136.

12 Gallup-Healthways. Gallup daily methodology, 2014.

13 Kahneman D, Riis J. Living, and thinking about it: Two perspectives on life. In: Huppert FA, Baylis N, Keverne B, eds. The science of wellbeing: Oup Oxford, 2005: 285-304.

14 Diener E. Guidelines for national indicators of subjective well-being and III-Being. Appl Res Qual Life 2007;1:151-7.

15 Diener E, Seligman MEP. Beyond money: toward an economy of well-being. Psychol Sci Public Interest 2004;5:1-31.

16 Kahneman D, Riis J. Living, and thinking about it: two perspectives on life. The science of well-being 2005:285-304.

17 Diener E. Assessing subjective well-being: progress and opportunities. Soc Indic Res 1994;31:103-57.

18 Steptoe A, Deaton A, Stone AA. Subjective wellbeing, health, and ageing. The Lancet 2015;385:640-8.

19 Gallup I. Gallup-Healthways well-being index: a methodology report for indexes, 2009.

20 Evers KE, Prochaska JO, Castle PH, et al. Development of an individual well-being scores assessment. Psychol Well Being 2012;2:2-9.

21 Hendra TJ, Taylor CD. A randomised trial of insulin on well-being and carer strain in elderly type 2 diabetic subjects. J Diabetes Complications 2004;18:148-54.

22 Chow CK, Lock K, Teo K, et al. Environmental and societal influences acting on cardiovascular risk factors and disease at a population level: a review. Int J Epidemiol 2009;38:1580-94.

23 Roos NP, Wennberg JE, McPherson K. Using diagnosis-related groups for studying variations in hospital admissions. Health Care Financ Rev 1988;9:53.

24 Kuh E, Welsch RE. Regression diagnostics: identifying influential data and sources of collinearity. Wiley-Interscience, 1980

25 Derges J, Clow A, Lynch R, et al. 'Well London' and the benefits of participation: results of a qualitative study nested in a cluster randomised trial. BMJ Open 2014;4:e003596.

26 Phillips G, Bottomley C, Schmidt E, et al. Measures of exposure to the Well London Phase-1 intervention and their association with health well-being and social outcomes. J Epidemiol Community Health 2014;68:597-605.
27 Prilleltensky I, Prilleltensky O. Promoting well-being: linking personal, organizational and community change. John Wiley \& Sons, 2007.

28 Arora A, Spatz E, Herrin J, et al. Population well-being measures help explain geographic disparities in life expectancy at the County level. Health Aff 2016;35:2075-82.

29 Riley C, Roy B, Herrin J, et al. Do pregnant women living in higher well-being populations in the USA experience lower risk of preterm delivery? A cross-sectional study. BMJ Open 2019;9:e024143. In press.

30 Riley C, Roy B, Herrin J, et al. Association of the overall well-being of a population with health care spending for people 65 years of age or older. JAMA Netw Open 2018;1:e182136.

31 Roy B, Riley C, Herrin J, et al. Identifying County characteristics associated with resident well-being: a population based study. PLOS One 2018;13:e0196720.

32 Semenza JC, March TL, Bontempo BD. Community-initiated urban development: an ecological intervention. J Urban Health 2007;84:8-20.

33 Semenza JC, Krishnasamy PV. Design of a health-promoting neighborhood intervention. Health Promot Pract 2007;8:243-56.

34 Singh JA, Borowsky SJ, Nugent S, et al. Health-Related quality of life, functional impairment, and healthcare utilization by veterans: Veterans' quality of life study. J Am Geriatr Soc 2005;53:108-13.

35 Fowler JH, Christakis NA. Dynamic spread of happiness in a large social network: longitudinal analysis over 20 years in the Framingham heart study. BMJ 2008;337:a2338.

36 Fowler JH, Christakis NA. Cooperative behavior cascades in human social networks. Proc Natl Acad Sci U S A 2010;107:5334-8.

37 Sampson RJ. Neighborhood-level context and health: lessons from sociology. Nueva York: Oxford University Press, 2003.

38 Egan M, Tannahill C, Petticrew M, et al. Psychosocial risk factors in home and community settings and their associations with population health and health inequalities: a systematic meta-review. BMC Public Health 2008;8:239.

39 Murayama H, Fujiwara Y, Kawachi I. Social capital and health: a review of prospective multilevel studies. Journal of Epidemiology 2012;22:179-87

40 Sundquist J, Johansson S-E, Yang M, et al. Low linking social capita as a predictor of coronary heart disease in Sweden: a cohort study of 2.8 million people. Soc Sci Med 2006;62:954-63

41 Kawachi I, Berkman L, cohesion S. Social capital, and health. Social epidemiology 2000;174.

42 Cradock AL, Kawachi I, Colditz GA, et al. Neighborhood social cohesion and youth participation in physical activity in Chicago. Soc Sci Med 2009;68:427-35.

43 Christakis NA, Fowler JH. The collective dynamics of smoking in a large social network. New England Journal of Medicine 2008;358:2249-58

44 Echeverría S, Diez-Roux AV, Shea S, et al. Associations of neighborhood problems and neighborhood social cohesion with mental health and health behaviors: the multi-ethnic study of atherosclerosis. Health Place 2008;14:853-65.

45 Samuel LJ, Dennison Himmelfarb CR, Szklo M, et al. Social engagement and chronic disease risk behaviors: the multi-ethnic study of atherosclerosis. Prev Med 2015;71:61-6.

46 Christakis NA, Fowler JH. The spread of obesity in a large social network over 32 years. N Engl J Med 2007;357:370-9.

47 Glanz K, Rimer BK, Viswanath K. Health behavior and health education: theory, research, and practice. John Wiley \& Sons, 2008.

48 Rodríguez-Artalejo F, Guallar-Castillón P, Herrera MC, et al. Social network as a predictor of hospital readmission and mortality among older patients with heart failure. J Card Fail 2006;12:621-7.

49 Kansagara D, Englander $\mathrm{H}$, Salanitro A, et al. Risk prediction models for hospital readmission: a systematic review. JAMA 2011;306:1688-98.

50 Diez Roux AV, Mair C. Neighborhoods and health. Ann N Y Acad Sci 2010;1186:125-45.

51 Johnson TV, Abbasi A, Master VA. Systematic review of the evidence of a relationship between chronic psychosocial stress and C-reactive protein. Mol Diagn Ther 2013;17:147-64.

52 Cagney KA, Cornwell EY. Neighborhoods and health in later life: the intersection of biology and community. Annual Review of Gerontology and Geriatrics 2010;30:323-48.

53 Black PH, Garbutt LD. Stress, inflammation and cardiovascular disease. J Psychosom Res 2002;52:1-23.

54 Hamer M. Psychosocial stress and cardiovascular disease risk: the role of physical activity. Psychosom Med 2012;74:896-903.

55 Lu X-T, Zhao Y-X, Zhang Y, et al. Psychological stress, vascular inflammation, and atherogenesis: potential roles of circulating cytokines. J Cardiovasc Pharmacol 2013;62:6-12. 
56 Steptoe A, Hamer M, Chida Y. The effects of acute psychological stress on circulating inflammatory factors in humans: a review and meta-analysis. Brain Behav Immun 2007;21:901-12.

57 McEWEN BS, Seeman T. Protective and damaging effects of mediators of stress: elaborating and testing the concepts of allostasis and allostatic load. Ann N Y Acad Sci 1999;896:30-47.

58 Giltay EJ, Kamphuis MH, Kalmijn S, et al. Dispositional optimism and the risk of cardiovascular death: the Zutphen elderly study. Arch Intern Med 2006;166:431-6.

59 Boehm JK, Kubzansky LD. The heart's content: the association between positive psychological well-being and cardiovascular health. Psychol Bull 2012;138:655-91.

60 Boehm JK, Peterson C, Kivimaki M, et al. A prospective study of positive psychological well-being and coronary heart disease. Health Psychology 2011;30:259-67.

61 Hernandez R, Kershaw KN, Siddique J, et al. Optimism and cardiovascular health: multi-ethnic study of atherosclerosis (MESA). Health Behav Policy Rev 2015;2:62-73.
62 Kubzansky LD, Thurston RC. Emotional vitality and incident coronary heart disease: benefits of healthy psychological functioning. Arch Gen Psychiatry 2007;64:1393-401.

63 Roy B, Diez-Roux AV, Seeman T, et al. Association of optimism and Pessimism with inflammation and hemostasis in the multi-ethnic study of atherosclerosis (MESA). Psychosom Med 2010;72:134-40.

64 Prior A, Vestergaard M, Davydow DS, et al. Perceived stress, multimorbidity, and risk for hospitalizations for ambulatory Caresensitive conditions. Med Care 2017;55:131-9.

65 Jorgensen BS, Jamieson RD, Martin JF. Income, sense of community and subjective well-being: combining economic and psychological variables. J Econ Psychol 2010;31:612-23.

66 Bindman AB, Grumbach K, Osmond D, et al. Preventable hospitalizations and access to health care. JAMA 1995;274:305-11.

67 Ansari Z, Laditka JN, Laditka SB. Access to health care and hospitalization for ambulatory care sensitive conditions. Med Care Res Rev 2006;63:719-41. 